\title{
Coin-cell Supercapacitors Based on CVD Grown and Vertically Aligned Carbon Nanofibers (VACNFs)
}

\author{
Amin M. Saleem ${ }^{1,2, *}$, Andrea Boschin ${ }^{3}$, Du-Hyun Lim ${ }^{3}$, Vincent Desmaris ${ }^{1}$, Patrik Johansson ${ }^{3}$, \\ Peter Enoksson ${ }^{2}$ \\ ${ }^{1}$ Smoltek AB, Regnbågsgatan 3, SE-417 55 Gothenburg, Sweden \\ ${ }^{2}$ Micro and Nanosystems Group, Electronics Materials and Systems Laboratory, Department of \\ Microtechnology and Nanoscience, Chalmers University of Technology, SE-412 96 Gothenburg, \\ Sweden \\ ${ }^{3}$ Department of Physics, Chalmers University of Technology, SE-412 96 Gothenburg, Sweden \\ *Email: $\underline{\text { amin@ @smoltek.com }}$
}

doi: $10.20964 / 2017.07 .46$

Received: 14 March 2017 / Accepted: 29 April 2017 / Published: 12 June 2017

\begin{abstract}
Complete supercapacitors (SCs) comprising vertically aligned carbon nanofibers (VACNFs) as electrode materials have been assembled as coin-cells. The VACNFs were grown directly onto the current collector by direct current plasma enhanced chemical vapor deposition (DC-PECVD), thereby providing excellent contact with the current collector, but also eliminating the need of any binder. The vertical alignment facilitates fast ion transport and the electrolyte to access the entire surface of the CNFs. The morphology of the VACNFs was evaluated by scanning electron microscopy (SEM), while the performance was assessed by several methods: cyclic voltammetry (CV), electrochemical impedance spectroscopy (EIS) and device related cycling by galvanostatic charge/discharge. The capacitance, $3.64 \mathrm{mF} / \mathrm{cm}^{2}$, is $>15$ times higher than the capacitance of a coin-cell without CNFs and the cyclic performance shows these proof-of-concept SCs to retain $>80 \%$ of the capacitance after 2000 full charge/discharge cycles. The direct growth of VACNFs as electrodes at the current collector opens pathways for SC production using existing coin-cell battery production technology.
\end{abstract}

Keywords: VACNF; PECVD; coin-cell; supercapacitor

\section{FULL TEXT}

(C) 2017 The Authors. Published by ESG (www.electrochemsci.org). This article is an open access article distributed under the terms and conditions of the Creative Commons Attribution license (http://creativecommons.org/licenses/by/4.0/). 